\title{
Evaluation of glucose metabolism in three horses with lower motor neuron degeneration
}

\author{
Johannes H. van der Kolk, DVM, PhD; Kim E. P. M. Rijnen, DVM; \\ Françoise Rey, DVM; Ellen de Graaf-Roelfsema, DVM; Guy C. M. Grinwis, DVM; \\ Inge D. Wijnberg, DVM, PhD
}

\begin{abstract}
Objectives-To determine whether increased glucose metabolism is the potential cause of the decreased plasma glucose curve determined after oral glucose tolerance testing in horses with lower motor neuron degeneration.
\end{abstract}

Animals-3 horses with signs suggestive of lower motor neuron degeneration, 1 horse with malignant melanoma with multiple metastases, and an obese but otherwise healthy horse.

Procedures-Glucose metabolism was assessed by use of the hyperglycemic clamp and euglycemic hyperinsulinemic clamp techniques.

Results-Mean rate of glucose metabolism of horses with lower motor neuron degeneration was significantly greater (mean, 3.7 times greater than control horses; range, 2.1 to 4.8 times greater) than that reported in 5 healthy control horses $141 \pm 13 \mu \mathrm{mol} / \mathrm{kg} / \mathrm{min}$ vs $11 \pm 4.5 \mu \mathrm{mol} / \mathrm{kg} / \mathrm{min}$, respectively). In addition, one of the affected horses, an 8-year-old warmblood gelding, had a 5.6times increased sensitivity to exogenously administered insulin, compared with that reported in 5 healthy control horses. Pancreatic insulin secretion was not insufficient in horses with lower motor neuron degeneration. Findings in the 2 diseased control horses were unremarkable.

Conclusions and Clinical Relevance-Increased glucose metabolism in horses with lower motor neuron degeneration may be the cause of the decreased plasma glucose curve detected after oral glucose tolerance testing. This finding could aid in developing supportive treatments with respect to adequate glucose and vitamin $\mathrm{E}$ supplementation. (Am J Vet Res 2005;66:271-276)

Th approximately $50 \%$ of horses with equine lower Imotor neuron disease (EMND), the plasma glucose curve is decreased after oral glucose tolerance testing. ${ }^{1}$ Equine lower motor neuron disease is a neurodegenerative disorder of the somatic lower motor neurons of horses. Horses with the subacute form have acute onset of trembling, muscle fasciculations, frequent shifting of weight in the hind limbs, and abnormal sweating and spend more time than normal lying

\footnotetext{
Received March 5, 2004.

Accepted May 28, 2004.

From the Departments of Equine Sciences (van der Kolk, Rijnen, Rey, de Graaf-Roelfsema, Wijnberg) and Pathobiology (Grinwis), Faculty of Veterinary Medicine, Utrecht University, Yalelaan12 3508 TD Utrecht, The Netherlands.

One case was presented as an abstract at the 42nd British Equine Veterinary Association Congress in Birmingham, UK, September 2003.

Address correspondence to Dr. van der Kolk.
}

down. Fatigue, poor performance, unusual gaits, and failure to gain weight are the most common complaints with the chronic form. Clinical signs appear as a result of oxidative damage to the somatic ventral motor neuron cells. If clinical, epidemiologic, and laboratory findings are suggestive (mild to moderately increased muscle enzyme activities and low plasma vitamin $\mathrm{E}$ concentration), EMND can be confirmed by microscopic examination of a muscle biopsy specimen or necropsy. ${ }^{1,2}$ Equine lower motor neuron disease resembles progressive spinal muscle atrophy (PSMA) in humans rather than amyotrophic lateral sclerosis (ALS). Equine lower motor neuron disease differs from classical ALS in that upper motor neuron pyramidal tracts are not involved. 3,4

Like horses with EMND, horses with polysaccharide storage myopathy (PSSM) have lower blood glucose concentrations after oral administration of glucose..$^{5}$ Glucose usage and production are regulated by insulin, which is synthesized and secreted by the $\beta$ cells of the islets of Langerhans in the pancreas. To study glucose metabolism and insulin resistance, a glucose clamp technique was developed by Andres et $\mathrm{al}^{6}$ in 1966. There are 2 types of glucose clamp techniques validated for use in horses: the hyperglycemic clamp technique and the euglycemic hyperinsulinemic clamp technique. ${ }^{7}$ In typical glucose tolerance tests, the dose of glucose is fixed and the measure of tolerance is the plasma glucose concentration. In the clamp techniques, the plasma glucose concentration is fixed and the glucose administered becomes the measure of tolerance. The hyperglycemic clamp technique allows quantification of the sensitivity of $\beta$ cells to glucose and is used to increase the plasma glucose concentration acutely to a fixed hyperglycemic plateau and maintain it at that concentration for approximately 2 hours, thereby suppressing endogenous hepatic glucose production. The euglycemic hyperinsulinemic clamp technique allows quantification of the sensitivity of tissues to insulin, and the induced supraphysiologic plasma insulin concentrations are necessary to produce a maximal response of glucose uptake by tissues and inhibit endogenous hepatic glucose production.

Insulin resistance is defined as a condition in which normal concentrations of insulin produce a subnormal physiologic response. ${ }^{8}$ The principle of both clamp techniques is that the rate of glucose infusion required to maintain a steady state is an index of glucose metabolism. ${ }^{9}$ With reference to the euglycemic hyperinsulinemic clamp technique, the rate of glucose infusion required to maintain euglycemia equals the 
quantity of glucose taken up by all tissues in response to exogenous insulin administration, provided that the endogenous glucose entry rate remains constant. The amount of glucose metabolized divided by the plasma insulin concentration during the steady state of the euglycemic hyperinsulinemic clamp technique reflects the quantity of glucose metabolized per unit of insulin in plasma and, as a result, is a reasonable index of the sensitivity of tissues to exogenous insulin.

The objective of the study reported here was to determine whether increased glucose metabolism is the potential cause of the decreased plasma glucose curve detected after oral glucose tolerance testing, by use of the hyperglycemic clamp technique as the gold standard, in horses with lower motor neuron degeneration.

\section{Materials and Methods}

Horses-Three Dutch Warmblood horses (a 7-year-old mare, an 8-year-old gelding, and a 2-year-old stallion, indicated as horses 1,2 , and 3 , respectively) with lower motor neuron degeneration were included in the study predominantly on the basis of clinical findings (weight loss despite good appetite, abnormally low head carriage with preference of feet placed under the body, muscle trembling, profuse sweating, excessive recumbency with normal postural response and correction response, lateral thoracic reflex, pain perception, tail tonus and anal reflex, and no deficits of the cranial nerves); motor unit action potential (MUP) analysis (mean number of broad polyphasic MUPs increased 5.6 times and number of complex MUPs increased 4.3 times as recorded in the subclavian, triceps, splenic, gluteal, lateral vastus, and descending pectoral muscles indicating generalized neuropathy, compared with healthy control horses ${ }^{10,11}$ ); and laboratory findings (plasma vitamin E concentration and muscle enzyme activities)

Two horses were used as diseased control horses, including a 14-year-old Dutch warmblood gelding (horse 4; only the hyperglycemic clamp test performed) that weighed $553 \mathrm{~kg}$ and had a large malignant melanoma in the wall of right auditory diverticulum (euthanatized because of metastases to cervical and shoulder muscles, abdominal cavity, and left kidney) and a 4-year-old obese Friesian gelding (horse 5; hyperglycemic and euglycemic hyperinsulinemic clamp tests performed) that weighed $548 \mathrm{~kg}$ (body condition score, ${ }^{12} 8$ basal plasma glucose $[5.0 \mathrm{mmol} / \mathrm{L}]$ and insulin $[28.0 \mathrm{pmol} / \mathrm{L}]$ concentrations were within reference ranges ${ }^{13}$ ).

Glucose clamp studies-Techniques used in the study reported here were based on the studies of Defronzo et $\mathrm{al}^{9}$ and Elmahdi, ${ }^{a}$ although some adjustments were made as reported previously. ${ }^{\top}$ One polyvinylchloride catheter was placed in each jugular vein after food was withheld for 12 hours. For the hyperglycemic clamp test, one of the catheters was used for infusion of glucose and the other catheter was used for obtaining blood samples at 10-minute intervals, as described by Bergman et al. ${ }^{14} \mathrm{~A}$ priming dose of $3.35 \mu \mathrm{mol}$ of glucose $/ \mathrm{kg}$ of body weight as a $50 \%$ solution was administered IV within 2 minutes to induce hyperglycemia ( $\geq 9.0$ $\mathrm{mmol} / \mathrm{L}$ ) rapidly. During the experiment, every 10 minutes, 2 blood samples were taken for measurement of the concentrations of glucose (heparinized blood syringe) and insulin (lithium heparin tube). Within 2 minutes, the glucose concentration of the 10-minute heparinized blood sample was determined by use of an automated analyzer. ${ }^{b}$ When the concentration of glucose decreased to $<9.0 \mathrm{mmol} / \mathrm{L}$, a glucose infusion (as a 50\% solution) was started at a mean rate of $368 \pm 121 \mathrm{~mL} / \mathrm{h}$ on the basis of data obtained from normal horses and by taking into account the body weight of the individual horse. The glucose infusion was stopped after maintaining a steady state of the blood glucose concentration for 30 minutes. A sample of urine for determination of glucose concentration was collected within 15 minutes after cessation of the glucose infusion. Plasma insulin concentration was determined in 4 samples taken during the hyperglycemic steady state in 10-minute intervals. Plasma was separated and stored at $-20^{\circ} \mathrm{C}$ until analysis of insulin was performed. Plasma insulin concentration was measured by use of a radioimmunoassay $\mathrm{kit}^{\mathrm{c}}$ validated for use in horses. ${ }^{13}$

The euglycemic hyperinsulinemic clamp test was performed by placing 1 catheter in each jugular vein after food was withheld for 12 hours. One of the catheters was used for infusion of glucose as a $50 \%$ solution and insulin, ${ }^{\mathrm{d}}$ whereas the other catheter was used for obtaining blood samples. A priming dose of $45 \mathrm{mU}$ of insulin/ $\mathrm{kg}$ dissolved in $50 \mathrm{~mL}$ of sodium chloride as a $0.9 \%$ solution was given IV within 10 minutes to induce hyperinsulinemia (plasma insulin concentration > $1,435 \mathrm{pmol} / \mathrm{L}$ ). Immediately after administration of the priming dose of insulin, insulin infusion was started with a constant rate infusion of $6 \mathrm{mU} / \mathrm{kg} / \mathrm{min}$. Glucose infusion was started simultaneously with an infusion rate of $8.6 \mu \mathrm{mol} / \mathrm{kg} / \mathrm{min}$, as described by Elmahdi. ${ }^{a}$ During the insulin and glucose infusions, blood samples were taken every 10 minutes. The blood glucose concentration was assayed within 2 minutes from these 10-minute samples by use of an automated analyzer. ${ }^{b}$ Glucose infusion rate was adjusted when the preceding blood glucose value differed from the euglycemic concentration (range, 3.9 to $5.6 \mathrm{mmol} / \mathrm{L}$ ). Plasma insulin concentration was determined in 4 samples (lithium heparin tube) taken during the steady state of the blood glucose concentration at 10-minute intervals. Plasma was separated and stored at $-20^{\circ} \mathrm{C}$ until insulin concentrations were measured by means of a radioimmunoassay kit ${ }^{\mathrm{c}}$ validated for use in horses. ${ }^{13}$

During steady state of the blood glucose concentration, the glucose infusion rate must equal the glucose metabolism rate, provided that endogenous glucose production is completely suppressed by hyperinsulinemia or hyperglycemia The glucose metabolism rate was computed as the following

$$
\begin{aligned}
& \mathrm{M}(\mathrm{mmol} / \mathrm{kg} / \mathrm{min})=\mathrm{INF}(\mathrm{mmol} / \mathrm{kg} / \mathrm{min})- \\
& \mathrm{UC}(\mathrm{mmol} / \mathrm{kg} / \mathrm{min})-\mathrm{SC}(\mathrm{mmol} / \mathrm{kg} / \mathrm{min})
\end{aligned}
$$

where $\mathrm{M}$ is glucose metabolism rate, INF is glucose infusion rate, UC is rate of urinary glucose loss, and SC is the so-called space correction factor. ${ }^{9}$ In the hyperglycemic and euglycemic hyperinsulinemic clamp tests, the plasma glucose concentration is not maintained constant perfectly and a correction must be made. The space correction factor adjusts for glucose that has been added or removed from the glucose space (ie, extracellular volume). The plasma glucose concentrations at the beginning $\left(G_{1}\right)$ and end $\left(G_{2}\right)$ of the 10-minute period are considered. The space correction is calculated as follows:

$$
\mathrm{SC}(\mathrm{mmol} / \mathrm{kg} / \mathrm{min})=\left(G_{2}-G_{1}\right) \times 0.019 .^{7}
$$

With reference to the hyperglycemic clamp test only, a small correction for urinary glucose loss must be made. The duration of glucose infusion was approximately 2 hours. To calculate the amount of glucose loss via urine during this period, the urine glucose concentration was determined in urine collected within 15 minutes after ending the hyperglycemic clamp test. To calculate the rate of urinary glucose loss, the published model ${ }^{7}$ was adjusted by estimating urine production as $20 \mathrm{~mL} / \mathrm{kg} / 24 \mathrm{~h}$ (approx $10 \mathrm{~L} / 24 \mathrm{~h}^{15}$ ). The formula for rate of urinary glucose loss was as follows:

UC $(\mathrm{mmol} / \mathrm{kg}$ of body weight $/ \mathrm{min})=$ urinary glucose concentration $(\mathrm{mmol} / \mathrm{L})$ : (body weight $\times 120){ }^{7}$ 
The plasma insulin concentration (pmol/L) was determined during the steady state of the blood glucose concentration. In the hyperglycemic clamp test, this is a measure of the $\beta$-cell response to glucose. During hyperglycemia, glucose uptake can be enhanced; consequently, the glucose metabolism rate can overestimate the amount of insulinmediated glucose uptake. This can be corrected by computing the ratio of the glucose metabolism rate to the plasma insulin concentration. The mean glucose metabolism rates and the aforementioned ratios were calculated from 3 measurements/horse, whereas the mean plasma glucose and insulin concentrations were calculated from 4 measurements.

The clamp tests as well as the electromyographic examinations were performed in conscious standing horses restrained in stocks. When both clamp tests were performed in the same horse, the hyperglycemic clamp test always preceded the euglycemic hyperinsulinemic clamp test with a 48 hour interval between tests.

Pathology studies-Because of the poor prognosis, the horses were euthanatized at their owner's request. Specimens were taken from the cerebral cortex; cerebellum; medulla oblongata; tractus mesencephalicus; and cervical, thoracic, and lumbar segments of the spinal cord, including the intumescentia cervicalis and lumbalis. In addition, samples were taken from several autonomic ganglia (trigeminal ganglion, cranial mesenteric ganglion, stellate ganglion, and celiac ganglion).

For histologic examination, muscle specimens were fixed in $4 \%(\mathrm{w} / \mathrm{v})$ phosphate-buffered paraformaldehyde, sectioned at $5 \mu \mathrm{m}$, and stained with H\&E. In addition, NADH, cytochrome c oxidase, succinate dehydrogenase, acid phosphatase, periodic acid Schiff, ATP-ase ( $\mathrm{pH}, 4.3$ and 9.4), Sudan black B, and Oil red O stains were performed on subclavian, triceps, and lateral vastus muscle tissues frozen in isopentane (precooled in liquid nitrogen) and stored at $-80^{\circ} \mathrm{C}$.

Assays-Plasma insulin and glucose concentrations were determined as described. ${ }^{13}$ Other blood constituents were measured by use of routine methods with an automated analyzer from blood samples obtained before the clamp tests.

Statistical analyses-The results of the glucose clamp tests were compared with those of 5 healthy warmbloods (condition score, 5) as described. ${ }^{7}$ The significance of differences between the groups was assessed by use of the MannWhitney test (2-tailed). Values of $P<0.05$ were considered significant. The results are presented as mean \pm SD with $95 \%$ confidence intervals (CIs).

\section{Results}

Glucose clamp tests in healthy control horsesOn the basis of urine production estimated as $20 \mathrm{~mL} / \mathrm{kg} / 24 \mathrm{~h}$, the mean rate of glucose metabolism during the hyperglycemic clamp test was $10.7 \pm 4.5$ $\mu \mathrm{mol} / \mathrm{kg} / \mathrm{min}$ (95\% CI, 1.6 to $19.8 \mu \mathrm{mol} / \mathrm{kg} / \mathrm{min}$ ) and the mean glucose metabolism rate-to-plasma insulin concentration ratio was $0.17 \pm 0.15$ (95\% CI, -0.14 to 0.48 ) in 5 healthy control horses following recalculation of previously published data of those control horses. $^{\top}$ Mean urinary glucose loss rate was $3.5 \pm 2.1 \%$ of the glucose metabolism rate. When urine production was estimated as $40 \mathrm{~mL} / \mathrm{kg} / 24 \mathrm{~h}$, the mean glucose metabolism rate during the hyperglycemic clamp test decreased, although not significantly, to $10.4 \pm 3.1$ $\mu \mathrm{mol} / \mathrm{kg} / \mathrm{min}$ and was associated with a urinary glucose loss rate that was $7.3 \pm 4.6 \%$ of the glucose metabolism rate. During the steady state of the blood glucose concentration in the model we used, a 5\% increase in the glucose infusion rate, initial plasma glucose concentration, urinary glucose concentration, and urinary volume changed the rate of glucose metabolism by $5.1 \%$, $55.1 \%,-0.1 \%$, and $-0.1 \%$, respectively. A $10 \%$ increase in the glucose infusion rate, initial plasma glucose concentration, urinary glucose concentration, and urinary volume changed the rate of glucose metabolism by $10.2 \%, 110.1 \%,-0.16 \%$, and $-0.16 \%$, respectively.

Horses with lower motor neuron degenerationThe hyperglycemic clamp test was performed in all 3 horses with degeneration of lower motor neurons (Table 1). In horse 3, the glucose infusion was stopped after 80 minutes because the mean space correction was within the reference range obtained from the published values for the 5 healthy horses ${ }^{7}$ after 50 minutes. Mean rate of glucose metabolism in the 3 horses with degeneration of the lower motor neurons was significantly $(P=0.025)$ greater than in the 5 healthy control horses $(41 \pm 13 \mu \mathrm{mol} / \mathrm{kg} / \mathrm{min}$ vs $11 \pm 4.5 \mu \mathrm{mol} / \mathrm{kg} / \mathrm{min}$, respectively), whereas mean body weight, mean plasma insulin concentration during the steady state of the blood glucose concentration, mean glucose metabolism rate-to-plasma insulin concentration ratio, and

Table 1-Variables obtained in 3 horses with lower motor neuron degeneration.

\begin{tabular}{|c|c|c|c|c|c|}
\hline \multirow[b]{2}{*}{ Variable } & \multicolumn{3}{|c|}{ Horse } & \multirow[b]{2}{*}{ Mean \pm SD } & \multirow{2}{*}{$\begin{array}{c}\text { Reference } \\
\text { range }\end{array}$} \\
\hline & 1 & 2 & 3 & & \\
\hline Age (y) & 7 & 8 & 2 & $5.7 \pm 2.6$ & NA \\
\hline $\mathrm{BW}(\mathrm{kg})$ & 521 & 416 & 402 & $446 \pm 53$ & NA \\
\hline CK (U/L̆) & 187 & 95 & 82 & $121 \pm 47$ & $<200$ \\
\hline AST (U/L) & 537 & 234 & 173 & $315 \pm 159$ & $125-275$ \\
\hline $\mathrm{LDH}(\mathrm{U} / \mathrm{L})$ & 1,534 & 533 & - & $1,034 \pm 501$ & $150-420$ \\
\hline Vitamin $\mathrm{E}(\mu \mathrm{mol} / \mathrm{L})$ & 1.5 & 1.2 & 5.2 & $2.6 \pm 1.8$ & $2-10$ \\
\hline Se $(\mu \mathrm{g} / \mathrm{L})$ & 245 & 214 & 189 & $216 \pm 23$ & $>70$ \\
\hline Lactate $(\mathrm{mmol} / \mathrm{L})$ & 0.4 & 0.4 & 0.6 & $0.47 \pm 0.09$ & $<1.0$ \\
\hline$\beta$-HBA (mmol/L) & 0.13 & 0.10 & NA & $0.12 \pm 0.02$ & $<0.39$ \\
\hline NEFA (mmol/L) & 0.28 & 0.51 & NA & $0.40 \pm 0.12$ & $<0.66$ \\
\hline $\mathrm{T}_{4}(\mathrm{nmol} / \mathrm{L})$ & 16 & 16 & 8 & $136 \pm .8$ & $20-42$ \\
\hline Urinary corticoids (nmol/L) & $>1,000$ & 453 & $>1,000$ & NA & $<323$ \\
\hline C:C ratio $\left(X 1^{-6}\right)$ & 33 & 21 & 75 & $43 \pm 23$ & $<21$ \\
\hline
\end{tabular}


Table 2-Variables (mean \pm SD) obtained via a hyperglycemic clamp test in 3 horses and a euglycemic hyperinsulinemic clamp test in 1 horse; all 3 horses had lower motor neuron degeneration.

\begin{tabular}{|c|c|c|c|c|c|}
\hline \multirow[b]{2}{*}{ Variable } & \multicolumn{3}{|c|}{ Horse } & \multirow[b]{2}{*}{ Mean \pm SD } & \multirow[b]{2}{*}{$\begin{array}{l}\text { Reference } \\
\text { range }\end{array}$} \\
\hline & 1 & 2 & 3 & & \\
\hline \multicolumn{6}{|l|}{$\begin{array}{l}\text { Euglycemic hyperinsulinemic } \\
\text { clamp tests }\end{array}$} \\
\hline $\begin{array}{l}\text { Steady state (min) } \\
\mathrm{M}(\mu \mathrm{mol} / \mathrm{kg} / \mathrm{min}) \\
\mathrm{M} / \mathrm{I} \\
\mathrm{SC} \text { (mmol/kg/min) } \\
\text { Plasma glucose (mmol/L) } \\
\text { I (pmol/L) }\end{array}$ & $\begin{array}{l}\text { NA } \\
\text { NA } \\
\text { NA } \\
\text { NA } \\
\text { NA } \\
\text { NA }\end{array}$ & $\begin{aligned} & 230 \\
& 51 \pm 3.6 \\
& .02 \pm 0.0032 \\
&-1.3 \pm 3.6 \\
& 4 \pm 0.14 \\
& 2,424 \pm 299\end{aligned}$ & $\begin{array}{l}\text { NA } \\
\text { NA } \\
\text { NA } \\
\text { NA } \\
\text { NA } \\
\text { NA }\end{array}$ & $\begin{array}{l}\text { NA } \\
\text { NA } \\
\text { NA } \\
\text { NA } \\
\text { NA } \\
\text { NA }\end{array}$ & $\begin{array}{c}\text { NA } \\
2.6-24.7 \\
-0.00026-0.0078 \\
-2.4-1.6 \\
3.9-5.6 \\
415-8,367\end{array}$ \\
\hline \multicolumn{6}{|l|}{ Hyperglycemic clamp test } \\
\hline $\begin{array}{l}\text { Steady state (min) } \\
\mathrm{M}(\mu \mathrm{mol} / \mathrm{kg} / \mathrm{min}) \\
\mathrm{M} / \mathrm{I} \\
\mathrm{SC}(\mathrm{mmol} / \mathrm{kg} / \mathrm{min}) \\
\mathrm{Plasma} \text { glucose }(\mathrm{mmol} / \mathrm{L}) \\
\text { I (pmol/L) } \\
\text { Urinary glucose }(\mathrm{mmol} / \mathrm{L})\end{array}$ & $\begin{array}{c}120 \\
23 \pm 5.5 \\
0.15 \pm 0.057 \\
-5.1 \pm 5.5 \\
9.7 \pm 0.37 \\
156 \pm 22.0 \\
13\end{array}$ & $\begin{array}{c}165 \\
51 \pm 0.5 \\
0.26 \pm 0.24 \\
1.9 \pm 0 \\
11.0 \pm 0.11 \\
431 \pm 247 \\
48.2\end{array}$ & $\begin{aligned} & 50 \\
& 48 \pm 5.7 \\
& 0.067 \pm 0.01 \\
& 0 \pm 4.1 \\
& 15.1 \pm 0.12 \\
& 721 \pm 23.5 \\
& 92.7\end{aligned}$ & $\begin{aligned} 112 & \pm 47 \\
41 & \pm 13 \\
0.16 & \pm 0.08 \\
-1.1 & \pm 3.0 \\
11.9 & \pm 2.3 \\
436 & \pm 231 \\
51 & \pm 33\end{aligned}$ & $\begin{array}{l}1.6-19.8 \\
-0.14-0.48 \\
-1.5-1.2 \\
\\
<258 \\
0\end{array}$ \\
\hline $\begin{array}{l}\mathrm{M}=\text { Rate of glucose } \mathrm{m} \\
\text { Results were based on } \\
\text { See Table } 1 \text { for remaind }\end{array}$ & $\begin{array}{l}\text { m. } S C= \\
\text { vations } / h \\
\text { ey. }\end{array}$ & orrection & Plasma in & 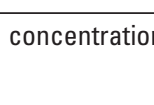 & \\
\hline
\end{tabular}

mean urinary glucose concentration differed, although not significantly, between groups (Table 2). The rate of glucose metabolism during the steady state of the hyperglycemic clamp test was $2.1,4.8$, and 4.5 times greater for horses 1 to 3 , respectively, compared with the mean value in healthy control horses. In addition, the euglycemic hyperinsulinemic clamp technique, performed in horse 2 only, revealed a 5.6-times increased sensitivity, compared with that reported in 5 healthy control horses to exogenous insulin, which was similar to decreased peripheral insulin resistance. Basal plasma glucose and lactate concentrations in horses with degeneration of lower motor neurons were within reference limits.

Diseased control horses-In comparison, in horse 4 , the mean (on the basis of 3 values) rate of glucose metabolism $(13.4 \pm 3.1 \mu \mathrm{mol} / \mathrm{kg}$ of body weight $/ \mathrm{min})$ and the ratio of that value to the plasma insulin concentration $(0.040 \pm 0.012)$ during the steady state of the hyperglycemic clamp test were within reference ranges. The mean rate of glucose metabolism $(9.7 \pm$ $3.9 \mu \mathrm{mol} / \mathrm{kg} / \mathrm{min}$ ) and the ratio of that value to the plasma insulin concentration $(0.026 \pm 0.011)$ during the steady state of the hyperglycemic clamp test, as well as the mean rate of glucose metabolism $(15.1 \pm 4.1$ $\mu \mathrm{mol} / \mathrm{kg} / \mathrm{min}$ ) and the ratio of that value to the plasma insulin concentration $(0.0039 \pm 0.0011)$ during the steady state of the euglycemic hyperinsulinemic clamp test, were also within reference ranges in horse 5 .

Pathologic findings-The clinicopathologic diagnosis was confirmed postmortem in all 3 horses, with histopathologic findings indicative of degeneration of motor neurons in the ventral horns of the spinal cord. The involved motor neurons had chromatolysis, swelling, and pallor with occasional absence of the nucleus (ghost cells). Also, some shrunken hypereosinophilic neurons and focal gliosis were observed. In addition, postmortem histologic examination of autonomic ganglia in horse 3 revealed neuronal degeneration with chromatolysis, formation of central cores (cosinophilia and peripheral vacuolization of the cytoplasm of a neuron), vacuolization, eosinophilia, and increased stromal cellularity. Furthermore, horse 1 had atrophic muscle fibers and horse 3 had muscle group atrophy characteristic of denervation atrophy. Evaluation of specimens stained with periodic acidSchiff stains did not reveal polysaccharide storage myopathy.

\section{Discussion}

Increased glucose metabolism might be the cause of the decreased plasma glucose curve detected after oral glucose tolerance testing in horses with lower motor neuron degeneration. Both the euglycemic hyperinsulinemic clamp test and the hyperglycemic clamp test are regarded as gold standards with reference to assessment of glucose metabolism. ${ }^{9}$

With the model we used, the initial plasma glucose concentration especially affected the rate of glucose metabolism. In equids, little is known about the effect of hyperglycemia on diuresis. However, horses with glucocorticoid excess caused by adenoma of the pituitary pars intermedia associated with diabetes mellitus do not always have polyuria-polydipsia. ${ }^{16}$ In addition, with the model we used, doubling of the urine volume resulted in a nonsignificant decrease in the rate of glucose metabolism (2.8\%).

As has been published before, ${ }^{7}$ the relationship $(\mathrm{r}=0.642)$ between glucose metabolism rates assessed in the 2 clamp tests was significant. In our study, both clamp tests were performed in 2 horses (horses 2 and 5), with similar results in the rate of glucose metabolism.

The glucose metabolism rate in both diseased control horses was in the reference range. In contrast, the mean glucose metabolism rate in 3 horses with lower motor neuron degeneration was increased 3.7 times, 
compared with that reported in 5 healthy control horses. Pancreatic insulin secretion was not insufficient in these horses, as indicated by results of the hyperglycemic clamp test. The low plasma thyroxine concentrations in all 3 horses ruled out hyperthyroidism and might reflect nonthyroidal illness (any chronic disease) that causes low plasma thyroxine concentrations.

Greatly increased rate of glucose metabolism was seen in combination with normal sensitivity to endogenous insulin as determined on the basis of the normal ratio of the rate of glucose metabolism to the plasma insulin concentration during the steady state of the hyperglycemic clamp test in all 3 horses with lower motor neuron degeneration. Abnormal glucose metabolism has previously been associated with motor neuron disease. Amyotrophic lateral sclerosis is the most common form of progressive motor neuron disease in humans. Although ALS at its onset may involve selective loss of function of only upper or lower motor neurons, it ultimately causes progressive loss of both categories of motor neurons, ${ }^{4}$ in contrast with EMND in which only lower motor neurons are affected. It is of interest that upper motor neuron pyramidal tracts, which are damaged in human ALS, are poorly developed in horses. ${ }^{3}$ Remarkably, the glucose infusion rate during an euglycemic hyperinsulinemic clamp test is significantly diminished in human ALS patients, compared with clinically normal and diseased controls, ${ }^{17}$ in contrast with the increased rate of glucose metabolism of the 3 horses with lower motor neuron degeneration reported here, as revealed by use of both clamp techniques. Reduced insulin sensitivity in humans with ALS is associated with a reduction in the number of monocyte binding sites. ${ }^{18}$

The amount of glucose metabolized by the body in horses is lower than in humans. ${ }^{7,8}$ Skeletal muscle, which makes up approximately $40 \%$ of the body mass of humans and other mammalian species, is the primary tissue responsible for the peripheral disposal of glucose in response to a glucose or insulin challenge or during exercise. Liver, muscle, and adipose tissues are the primary target tissues of insulin, rather than enterocytes. Glucose transport into myocytes is regulated by translocation of glucose transporters (eg, GLUT-4) to the cell surface, an event that is crucial for glucose uptake by skeletal muscle and fat. Available evidence supports the idea that it is the magnitude of GLUT-4 translocation that dictates the capacity of skeletal muscle to increase glucose transport activity. Interestingly, a 5.6-times increased sensitivity to exogenous insulin, compared with that reported in 5 healthy control horses, was determined on the basis of a single euglycemic hyperinsulinemic clamp test performed in a horse with lower motor neuron degeneration, possibly reflecting increased GLUT-4 translocation.

Given the fact that skeletal muscle is the primary tissue responsible for the peripheral disposal of glucose, comparison with PSSM is of interest. Although similar peak glucose concentrations were found in control horses and horses with PSSM during an IV glucose tolerance test, the latter group had significantly lower mean blood glucose concentrations from 0 to 180 minutes after IV glucose administration. ${ }^{5}$ As a con- sequence, these data suggest that various types of equine neuromuscular disease (denervating disease and primary metabolic myopathy) behave in a stereotypical way regarding glucose clearance, given that lower motor neuron degeneration is the primary process, reflecting the large role that skeletal muscle plays in whole-body glucose metabolism. With regard to PSSM, further research with the euglycemic hyperinsulinemic clamp test as the gold standard with reference to glucose metabolism would be of interest.

Because the plasma nonesterified fatty acid concentrations reflect lipolysis and were not increased in the horses reported here, it seems that increased glucose metabolism in horses with lower motor neuron degeneration is not accompanied by lipolysis. Obviously, the urinary corticoid excess, as seen in the horses reported here, did not induce lipolysis and might be associated with the stress of the condition. Metabolism of glucose generates ATP via glycolysis and mitochondrial oxidative phosphorylation. ${ }^{20}$ Because basal lactate concentrations were within reference range in horses with lower motor neuron degeneration, anaerobic glycolysis obviously did not take place. The question remains as to whether the decreased plasma concentration of vitamin E, an antioxidant, developed in response to the greatly increased rate of glucose metabolism (and associated mitochondrial oxidative phosphorylation) in horses with lower motor neuron degeneration.

Most of the oxygen consumed in the body is used in the mitochondria for substrate metabolism and ATP production. For every molecule of glucose, there is a requirement for 6 molecules of $\mathrm{O}_{2}$ for ATP production via carbohydrate catabolism. In comparison, the oxidation of stearic acid requires 26 molecules of $\mathrm{O}_{2}$. It has been estimated that for every 25 molecules of $\mathrm{O}_{2}$ reduced by normal respiration, 1 free radical is produced. Generation of reactive oxygen species is a normal process in the life of aerobic organisms. Vitamin E improves the free radical defense system. Results of several studies indicate a link between physical exercise, an increase in oxygen consumption, and free radical production. For example, prolonged heavy exercise may cause a transient reduction of tissue vitamin E content and a change of glutathione redox status in various body tissues. ${ }^{21,22}$ Interestingly, in a recent review, the question has been raised regarding whether a high carbohydrate diet increases antioxidant needs, particularly of fat-soluble vitamin $\mathrm{E}^{22}$

Lower motor neuron degeneration was diagnosed by use of MUP analysis as well as by histopathologic examination of motor neurons in the ventral horns of the spinal cord in all 3 horses in this report. Electromyographic examination, including MUP analysis, is sensitive in early antemortem detection of neurogenic changes and is a fairly noninvasive technique in horses. ${ }^{\mathrm{f}}$ Interestingly, horse 3 had MUP abnormalities as well as typical histopathologic changes, despite having normal plasma vitamin E concentration.

We conclude that increased glucose metabolism, possibly attributable to increased GLUT-4 translocation, is the potential cause of the decreased plasma glu- 
cose curve detected after oral glucose tolerance testing in horses with lower motor neuron degeneration. In addition, it has been reported that no change occurred in the activity and concentration of the small intestine membrane $\mathrm{Na}^{+}$/glucose-cotransporter in 2 horses with EMND. ${ }^{23}$ However, the hypothesis that increased GLUT-4 translocation is occurring needs to be tested. Furthermore, it is hypothesized that increased glucose metabolism might be the potential cause of the decreased plasma vitamin E concentration detected in horses with this disease.

a. Elmahdi BEM. Comparative aspects of glucose metabolism in camels, sheep, horses and ponies. PhD dissertation, Bovine Clinic, Veterinary School, University of Hannover, Hannover, Germany $1998 ; 101$.

b. ABL-605 radiometer, Radiometer America, Westlake, Ohio.

c. Diagnostic Products Corp, Los Angeles, Calif.

d. Actrapid recombinant human insulin $(100 \mathrm{U} / \mathrm{mL})$, Novo Nordisk A/S, Bagsvaerd, Denmark.

e. Beckman Coulter Inc, Miami, Fla.

f. Wijnberg ID. The diagnostic possibilities of EMG needle examination in the horse. PhD thesis, Department of Veterinary Medicine, Utrecht University, 2002.

\section{References}

1. Divers TJ, Mohammed HO, Cummings JF, et al. Equine motor neuron disease: findings in 28 horses and proposal of a pathophysiological mechanism for the disease. Equine Vet J 1994; 26:409-415.

2. Divers TJ, de Lahunta A, Hintz HF, et al. Equine motor neuron disease. Equine Vet Educ 2001;13:63-67.

3. Valentine BA, de Lahunta A, George C, et al. Acquired equine motor neuron disease. Vet Pathol 1994;31:130-138.

4. Brown RH Jr. Amyotrophic lateral sclerosis and other motor neuron diseases. In: Braunwald E, Fauci AS, Kasper DL, et al, eds. Harrison's principles of internal medicine. 15th ed. New York: McGrawHill Book Co, 2001;2412-2416.

5. De La Corte FD, Valberg SJ, MacLeay JM, et al. Glucose uptake in horses with polysaccharide storage myopathy. Am J Vet Res 1999;60:458-462.

6. Andres R, Swerdloff R, Pozefsky T, et al . Manual feedback technique for the control of glucose concentration. In: Skaggs LT, Jr ed. Automation in analytical chemistry. Mediad: New York 1966:486-491.

7. Rijnen KEPM and Kolk JH van der. Determination of reference range valuesindicative of glucosemetabolism and insulin resistance by use of glucose clamp techniques in horses and ponies. Am J Physiol 92:688-695.

8. Kahn CR. Insulin resistance, insulin sensitivity, and insulin unresponsiveness: necessary distinction. Metabolism 1978; 27:1893-1902.

9. DeFronzo RA, Tobin JD, Andres R. Glucose clamp technique: a method for quantifying insulin secretion and resistance. Am J Physiol 1979;237:E214-E223.

10. Wijnberg ID, Franssen $\mathrm{H}$, van der Kolk JH, et al. Quantitative analysis of motor unit action potentials in the subclavian muscle of healthy horses. Am J Vet Res 2001;63:198-203.

11. Wijnberg ID, Franssen H, van der Kolk JH, et al. Quantitative motor unit action potential analysis of skeletal muscles in the Warmblood horse. Equine Vet J 2002;34:556-561.

12. Henneke DR, Potter GD, Kreider JL, et al. Relationship between condition score, physical measurements and body fat percentage in mares. Equine Vet J 1983;15:371-372.

13. van der Kolk JH, Wensing T, Kalsbeek HC, et al. Laboratory diagnosis of equine pituitary pars intermedia adenoma. Domest Anim Endocrinol 1995;12:35-39.

14. Bergman RN, Finegood DT, Ader M. Assessment of insulin sensitivity in vivo. Endocrinol Rev 1985;6:45-86.

15. Schott HC. Renal physiology. In: Reed SM, Bayly WM, eds. Equine internal medicine. Philadelphia: WB Saunders Co, 1998;817-827.

16. van der Kolk JH, Kalsbeek HC, van Garderen E, et al Equine pituitary neoplasia: a clinical report of 21 cases (1990-1992). Vet Rec 1993;133:594-597.

17. Reyes ET, Perurena OH, Festoff BW, et al. Insulin resistance in amyotrophic lateral sclerosis. J Neurol Sci 1984;63:317-324.

18. Perurena OH, Festoff BW. Reduction in insulin receptors in amyotrophic lateral sclerosis correlates with reduced insulin sensitivity. Neurology 1987;37:1375-1379.

19. Henriksen EJ. Invited review: effects of acute exercise and exercise training on insulin resistance. J Appl Physio 2002;93:788-796.

20. Chen Y-T. Glycogen storage diseases and other inherited disorders of carbohydrate metabolism. In: Braunwald E, Fauci AS, Kasper DL, et al. Harrison's principles of internal medicine. 15th ed. New York: McGraw-Hill Book Co, 2001;2281.

21. Chance B, Sies H, Boveris A. Hydroperoxide metabolism in mammalian organs. Physiol Rev 1979;59:527-605.

22. Banerjee AK, Mandal A, Chanda D, et al. Oxidant, antioxidant and physical exercise. Mol Cell Biochem 2003;253:307-312

23. Benders NA, Dyer J, Wijnberg ID, et al. Evaluation of glucose tolerance and intestinal luminal membrane glucose transporter function in horses with equine motor neuron disease. Am J Vet Res 2005;66:93-99. 